\title{
Gas Turbine Engine Optimization at Conceptual Designing
}

\author{
Andrey Y. Tkachenko, Venedikt S. Kuz'michev, Ilia N. Krupenich and Viktor N. Rybakov \\ Samara National Research University, Department of Theory of Aircraft Engines, 34, Moskovskoye Shosse, Samara, 443086, Russia
}

\begin{abstract}
This article is a survey of the basic aspects of a gas turbine engine's conceptual designing and the optimization methods for solving problems at this stage. In the beginning, the purpose of the conceptual design is considered. Then, the methods of solving some problems are subsequently described. Finally, article provides information about the computer-aided means for solution of these problems, which were developed.
\end{abstract}

\section{Introduction}

Conceptual design is the initial stage of the engine design. Working process parameters, geometrical parameters of the flow path, control laws are selected at this stage. They should ensure maximum fuel, ecological, weight, cost efficiency in compliance with all regulations and restrictions.

Most of the conceptual design tasks (see Fig. 1) are essentially problems of multicriteria conditional parametric and structural optimization.

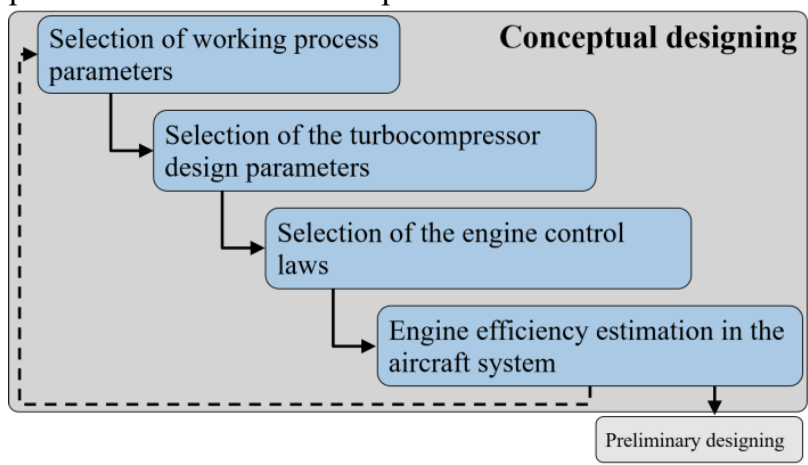

Figure 1. The tasks of the conceptual design.

Therefore, the crucial problem is the development of methods and models that can reliably, quickly and accurately find an adequate solution.

\section{Optimization of working process parameters}

The first task is the values selection of working process parameters that form a thermodynamic cycle [1]-[3]. Mathematical formulation of this problem is

$$
\begin{gathered}
X=\arg \left\langle\min _{x_{i}} \max _{Z_{j}} Z_{j}\left(x_{i}, p\right) \mid Q_{j}\left(x_{i}, p\right) \leq 0\right\rangle \\
Q\left(x_{i}, p\right)=\Sigma q_{k}\left(x_{i}, p\right)
\end{gathered}
$$

$$
\begin{gathered}
Z_{j}\left(x_{i}, p\right)=r_{j}\left(\frac{y_{j}\left(x_{i}, p\right)}{Y_{j}(p)}-1\right) \\
y_{j}\left(x_{i}, p\right)=\left[C_{\text {т`Км }}, M_{\mathrm{cy}+\mathrm{T}}, a, \ldots\right]
\end{gathered}
$$

Variable parameters are a total compressor pressure ratio, a combustor exit temperature, a bypass ratio, a fan pressure ratio and maybe some others.

In accordance with the system approach, the aircraft efficiency criteria should be used as performance indicators [4]-[6]. Some of which are a total mass of the power plant and fuel, a fuel cost per tonne-kilometre of transported cargo, an operating cost and so on.

The structure of the mathematical model is presented in Fig. 2.

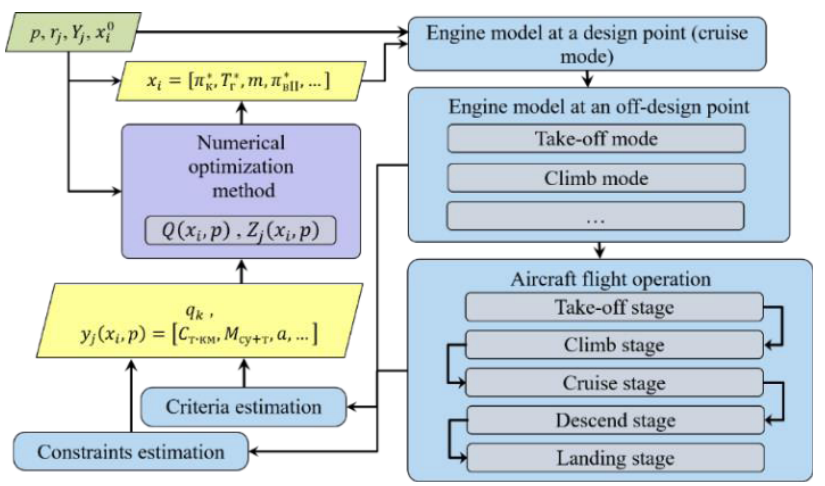

Figure 2. The structure of the mathematical model for optimization of the working process parameters.

After the working process parameters values were defined or refined for the current iteration, the design engine model is calculated. For turbofan engines, this calculation is usually performed for a cruise mode. Its results define the data for off design engine, such as, the flowpath areas at the main sections, the characteristic maps of the compressors and turbines.

Further, off-design engine model is calculated for various modes of operation. Thus, the diameter size of 
the engine, the powerplant weight and the engine performance can be defined.

As mentioned before, the important aspect is that the engine designing should be based on the aircraft performance estimation. Therefore, the next block performs the aircraft flight modelling.

Information about flight program, weight, geometric and aerodynamic characteristics of the airplane is used to obtain the required thrust level and, consequently, the operation mode of the engine at each point of the flight path.

The result of numerical integration of the aircraft dynamic equations is the flight duration and the total fuel consumption, which are used for criteria estimation.

The optimization module calculates values of the objective function and the termination criteria. For taking constrains into account the penalty method is well suited. If the termination condition is not achieved, the algorithm proposes new values of the variable parameters, and the calculation is reiterated.

Another important aspect is the multicriteria formulation of the problem. In this case, optimization task may be performed in two phases. In the first phase, the parameters are optimized in a single-criterion statement separately for each indicator, as shown in Fig. 3.

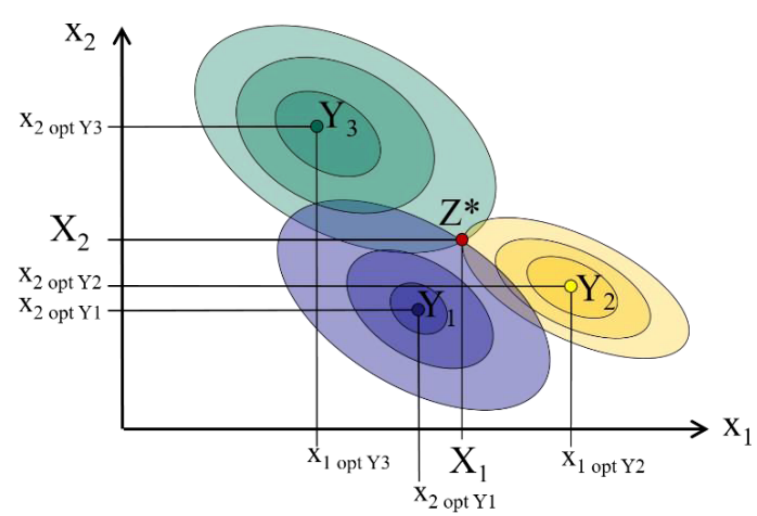

Figure 3. Optimization process phases.

Optimum indicator values are used to determine its normalized values in the next phase. So, in the second phase, the objective function is calculated as the maximum value from the set of normalized indicator values considering the constraints. Thus, the optimization problem in multi-criteria formulation applies the minimax principle. The Nelder-Mead method or differential evolution algorithm is commonly used for numerical optimization.

\section{Optimization of an engine family based on a unified engine core}

The modification of the base engine is common practice for designing of advanced engines with various applications. This approach provides high levels of reliability, service life of new engines and also reduces the time and cost of its development process.

The most complex part of engines is an engine core or a gas-generator. However, it is difficult to apply the same engine core in different engines, especially, if it was not originally designed for this purpose. Often, the engine core needs to be modified or scaled. The vivid example is the Rolls-Royce Trent engine family.

Therefore, a new method was developed, which allows to simultaneously optimize the working process parameters of the unified engine core and parameters of entire family of aircraft engines and energy power plants based on this engine core [7]. Mathematical formulation of this task and the model structure of this task are presented in Fig. 4.
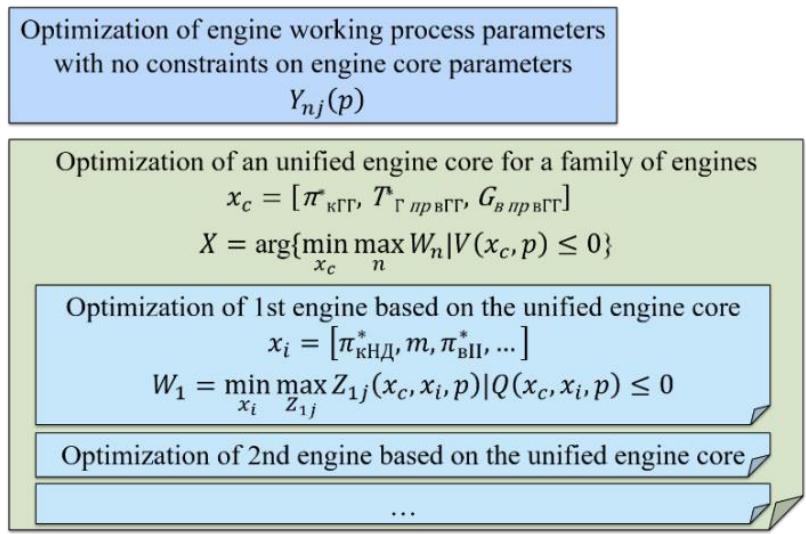

Figure 4. Model structure of optimization of an engine family based on a unified engine core.

This method differs from the previous one. In the first phase, the parameters are also optimized in a singlecriterion statement separately for each engine of the family and for each indicator. The result is a set of optimal engines with different engine cores.

In the second phase, the outer optimization loop is used for engine core parameters selection. The inner subtasks run parallel optimizing remaining working process parameters for each engine of the family.

Thus, optimization of the unified engine core and engine family is a combination of external and internal problems of multicriteria optimization.

This method is the most versatile, because a parameters optimization of a sole engine is only, in fact, its particular case.

\section{Optimization of the turbocompressor design parameters}

The next basic task of a gas turbine engine conceptual design is optimization of the turbocompressor design parameters. It can be formulated as follows.

$$
\begin{gathered}
X=\alpha \rho \gamma\left\{\min _{s} \min _{x_{s i}} F_{s}\left(x_{s i}, p\right) \mid Q\left(x_{s i}, p\right)\right. \\
F_{s}\left(x_{s i}, p\right)=\sum_{j} Z_{s j}\left(x_{s i}, p\right) \\
Z_{s j}\left(x_{s i}, p\right)=r_{s j}\left(\frac{y_{s j}\left(x_{s i}, p\right)}{Y_{s j}(p)}-1\right)
\end{gathered}
$$

Variable parameters are the geometrical parameters of blades and a flowpath, a number of blades in a blade row of turbines and compressors, as well as the parameters that define the scheme of the turbocompressor, such as a number of spools, types of compressors and turbines, a 
number of stages in the compressor and turbine spools and so on.

Optimization of the turbocompressor design parameters may be divided on two subtasks (see Fig. 5). The internal subtask is parametric optimization of geometrical parameters of blades and the number of blades in a blade row. The external subtask is structural optimization of the turbocompressor scheme.

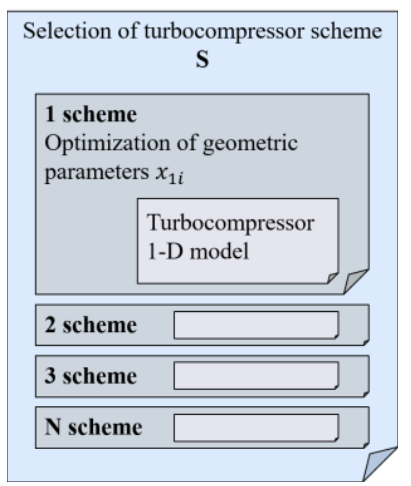

Figure 5. Task structure of optimization of turbocompressor design parameters.

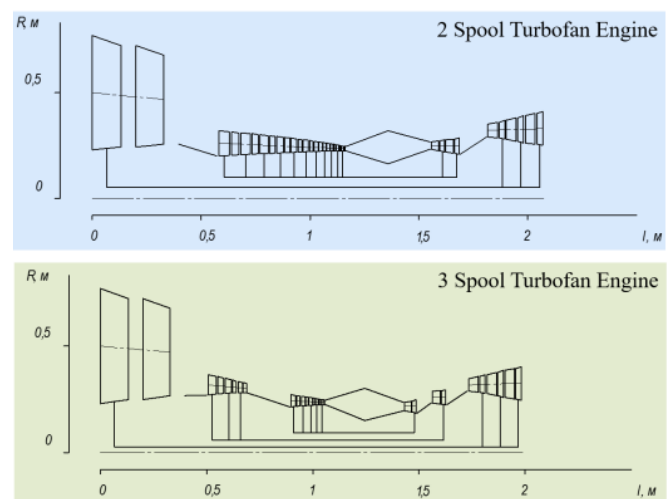

Figure 6. Results of turbocompressor design parameters optimization.

The performance estimation is performed using onedimensional models of the turbocompressor units and weight assessment models. The one-dimensional model reflects the influence of variable parameters on the unit's efficiency and the total engine efficiency at design and off-design points.

If there are different types of indicators (float and integer), it is better to use the additive value of the normalized criteria as the objective function for multicriteria optimization.

Figure 6 shows the results of turbocompressor design parameters optimization for two engines. They have the same thermodynamic parameters, but different schemes.

\section{Engine control optimization}

The aim of this task is to derive the optimal control law for engine operation managing during the aircraft flight [8], [9]. For numerical modeling a continuous flight process defined by a system of differential equations have to be replaced by a discrete multi-step process (see Fig. 7). In this case, the control law may be represented as a tabular function of the engine control parameters at each discrete step of the process. Values of engine control parameters in particular step uniquely identify a system transitions from one state to another [10].

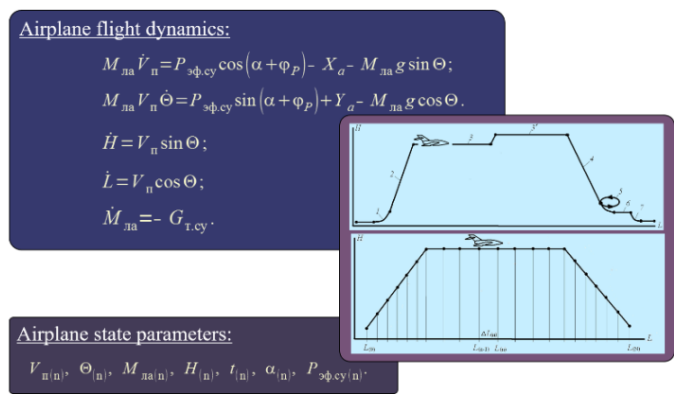

Figure 7. Aircraft flight process modelling.

Engine control optimization is a problem of finding a sequence of control parameters values $u$, which provide a minimum of the objective function at the end of the aircraft flight.

$$
\begin{gathered}
\boldsymbol{U}=\alpha \rho \gamma\left\{\min _{x_{i}} \max _{Z_{j}} Z_{j}(\{\boldsymbol{u}\}, p) \mid T(\{\boldsymbol{u}\}, p) \leq 0\right\}(8) \\
\boldsymbol{U}=\{\boldsymbol{u}\} *=\left\{u_{1}(L), u_{2}(L), \ldots u_{n}(L)\right\} * \\
T(\{\boldsymbol{u}\}, p)=\Sigma t_{k}(\{\boldsymbol{u}\}, p)+Q(\{\boldsymbol{u}\}, p)\left(10+\frac{n-i}{n}\right) \\
Q(\{\boldsymbol{u}\}, p)=\Sigma q(\{\boldsymbol{u}\}, p) \\
Z_{j}(\{\boldsymbol{u}\}, p)=r_{j}\left(\frac{y_{j}(\{\boldsymbol{u}\}, p)}{Y_{j}(p)}-1\right)
\end{gathered}
$$

The algorithm of this task is based on the numerical method of dynamic programming and the Bellman optimality principle. A system state at the end of a step depends only on the state at the beginning of this step and control parameters values at this step. Therefore, at the last step, it is easy to find the optimal control by means of a numerical method of parametric optimization. For the second last step, action is the same. However, changing the control at this step it is necessary to repeat control optimization at last step to obtain proper criteria values.

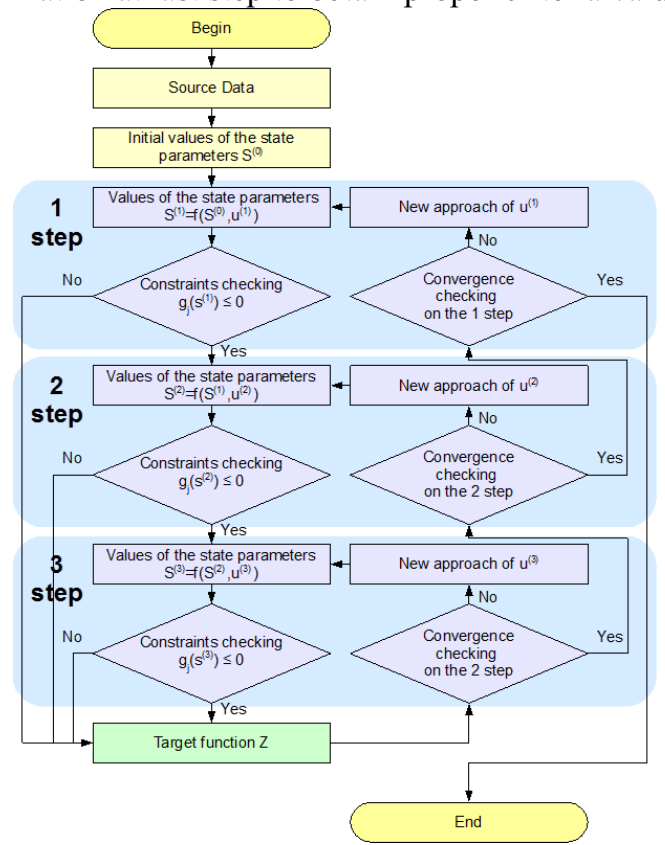

Figure 8. Scheme of Engine control optimization. 
Thus, this task can be represented as a sequence of nested optimization subtasks, so that control optimization at the first step is external to all others. For example, the control optimization algorithm of the three-step process is presented on the block diagram (see Fig. 8).

It should be mentioned that this algorithm is very time-expensive and demands high-performance computing facilities.

\section{Conclusions}

In this research we have investigated the methods and algorithms of solving such problems as:

- Optimization of the working process parameters at the design point of gas turbine engine;

- Optimization of the working process parameters of the unified engine core and the engine family based on it;

- Optimization of the turbocompressor design parameters; - Engine control optimization.

The main purpose of this paper has been to develop the effective and reliable optimization methods which can be used for creating of computer-aided tools for aircraft gas turbine engines designing.

Algorithms of numerical methods, basic functions, modeling tools are implemented as a standalone software framework CARCASE. Computer-aided means for complex technical systems engineering can be created using this framework and domain specific models, such as CAE-system ASTRA for example (Fig. 9).

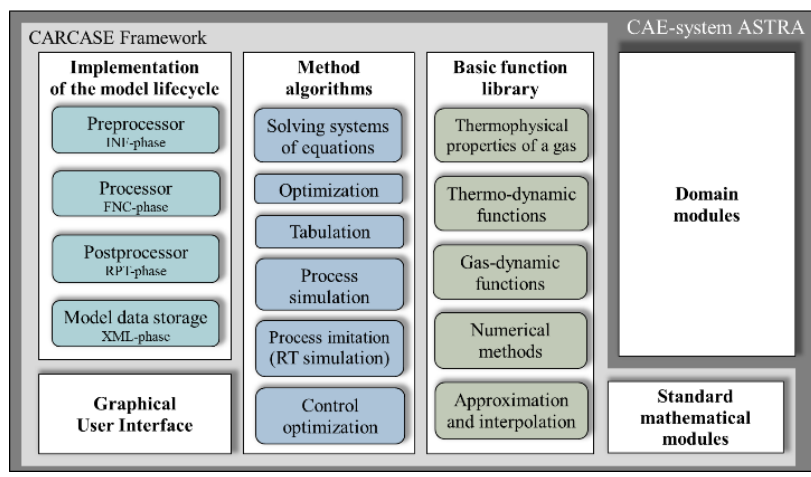

Figure 9. Structure of CAE-system ASTRA software.

CAE-system ASTRA is a computer software for solving of complex conceptual design problems, which are listed below:

- Computer modeling of engine working process;

- Thermodynamic analysis of a gas turbine engine cycle;

- Calculation at the design and off-design operation points;

- Evaluation of the impact of atmospheric and flight conditions;

- Performance prediction of a turbocompressor;

- Optimization of working process parameters;

- Optimization of turbocompressor design parameters;

- Optimization of engine control with aircraft flight modeling;

- Modeling and simulation of transient engine operation;

- Analysis of engine transient operation;

- Implementation of virtual test bench.

\section{Acknowledgments}

This work was supported by the Ministry of education and science of the Russian Federation in the framework of the implementation of the Program of increasing the competitiveness of Samara University among the world's leading scientific and educational centers for 2013-2020 years.

\section{Nomenclature}

$C_{\text {тккм }} \quad$ fuel consumption per ton of the payload per kilometer of distance, $[\mathrm{kg} /($ tons $\cdot \mathrm{km})]$;

$M_{\text {су+т }} \quad$ total mass of the power-plant and the fuel, consumed during the flight, $[\mathrm{kg}]$;

$a_{*} \quad$ net cost of transportation, [1/(tons $\left.\left.\cdot \mathrm{km}\right)\right]$;

$\pi^{*}$ fII secondary flow pressure ratio;

$m$ bypass ratio;

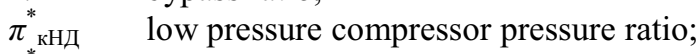

$\pi_{*}^{*}{ }^{*} \Gamma \Gamma \quad$ engine core compressor pressure ratio;

$\pi_{\Sigma}^{*} \quad$ overall pressure ratio;

$T^{*}$ Г.пр.вГГ specific turbine inlet temperature, normalized by the parameters at the engine core inlet, $[\mathrm{K}]$;

$G_{\text {В.пр.вГГ }}$ specific air flow rate, normalized by the parameters at the engine core inlet, $[\mathrm{kg} / \mathrm{s}]$;

$L \quad$ flight range, $[\mathrm{km}]$;

$p \quad$ set of source data;

$x \quad$ variable parameters;

$q \quad$ parametric constraint;

$Q \quad$ total parametric constraint for engine core parameters;

$V \quad$ total parametric constraint for engines parameters;

$t \quad$ process constraint;

$T \quad$ total process constraint;

$y \quad$ efficiency criterion of gas turbine engines or aircraft;

$Z \quad$ normalized value of efficiency criterion;

$n$ number of engine;

$U$ table of the control function values;

$i, j, k \quad$ indexes.

\section{References}

1. P. Ahmadi, I. Dincer, M.A. Rosen, Thermodynamic modeling and multi-objective evolutionary-based optimization of a new multigeneration energy system, Energy Conversion and Management, 76, (2013), pp. 282-300.

2. S. Campanari, Boncompagni, E. Macchi, Microturbines and trigeneration: Optimization strategies and multiple engine configuration effects, Journal of Engineering for Gas Turbines and Power, 126 (1), (2004), pp. 92-101.

3. S. Ramakrishnan, K.-Y. Teh, C.F. Edwards, Identification of optimal architecture for efficient simple-cycle gas turbine engines, $A S M E$ International Mechanical Engineering Congress and Exposition, Proceedings, 6, (2010), pp. 539-548.

4. E. Van Driel, R. Slingerland, N. Antoine, A framework for aircraft power systems optimization, 
Structural Dynamics and Materials Conference, 6, (2006), pp. 3894-3904.

5. A. Guha, D. Boylan, P. Gallagher, Determination of optimum specific thrust for civil aero gas turbine engines: A multidisciplinary design synthesis and optimization, Proceedings of the Institution of Mechanical Engineers, Part G: Journal of Aerospace Engineering, 227(3), pp. 502-527.

6. K.E. Sheldon, C.M. Anderson-Cook, W.F. O'Brien, Using computer modeling to optimize cost and maintain performance constraints for the production of aircraft turbine engines, Quality and Reliability Engineering International, 20 (5), (2004), pp. 541551.

7. V.S. Kuz'michev, V.V. Kulagin, A.Y. Tkachenko, I.N. Krupenich, V.N. Rybakov, Optimization of the turbofan engine with a given engine core: problem setting, Vestnik of Samara State Aerospace University, 5(36), vol. 1, (2012), pp. 165-169.

8. V.V.R. E Silva, W. Khatib, P.J. Fleming, Control system design for a gas turbine engine using evolutionary computing for multidisciplinary optimization, Controle y Automacao, 18 (4), (2007), pp. 471-478.

9. S. Kim, H. Thompson, P. Fleming, Active hierarchical fuzzy control for gas turbine altitude relighting using multi-objective optimization, Proceedings of the ASME Turbo Expo, 2, (2006), pp. 853-861.

10. V.S. Kuz'michev, A.Y. Tkachenko, V.N. Rybakov, Aircraft flight simulation during the optimization of the working process parameters of the gas turbine engines, Proceedings of the Samara Scientific Center of the Russian Academy of Sciences, vol.14, №1(2), (2012), pp. 491-494. 